\title{
The Enemy of My Enemy: When Firms Support Climate Change Regulation
}

\author{
Amanda Kennard
}

\begin{abstract}
Policies to mitigate global climate change entail significant economic costs. Yet a growing number of firms lobby in favor of regulation to mitigate carbon emissions. Why do firms support environmental regulations that directly increase production costs? This question is all the more puzzling in a globalized economy where regulation may undermine the competitiveness of domestic firms at home and abroad. By imposing differential costs on participants in the domestic market, policies designed to mitigate carbon emissions shift market share toward firms with low anticipated adjustment costs. I develop and test a model of climate change policymaking in the presence of market competition and open borders. Heterogeneity in adjustment costs induces a preference for regulation among low-cost firms. Firms facing import pressure-or export competition-may prefer stringent regulation if costs are sufficiently asymmetric. Firms embedded in global value chains also benefit if regulation raises the costs of domestically produced intermediate goods.
\end{abstract}

Policy efforts to mitigate global climate change are projected to impose significant economic costs on firms. Yet a large and growing number of firms lobby actively in favor of climate change cooperation and domestic regulation to mitigate carbon emissions. Support for mitigation policies can be found across a range of industries, from transportation and electronics to cement production and finance. Even within the oil and gas industry, infamous for its historically trenchant opposition to climate action, major players such as BP and Shell have come out in favor of policies designed to reduce carbon emissions.

Support for domestic regulation is especially puzzling in the context of an increasingly integrated global economy. Domestic regulation will raise energy costs, undermining domestic producers' competitiveness both at home and abroad. Consider the global aluminum industry. Aluminum smelting is energy intensive, with energy accounting for 20 percent of overall production costs. ${ }^{1}$ The US aluminum industry faces stiff competition from abroad. Yet when the US House of Representatives

1. Alcoa Corporation 2017. Aluminum is an internationally traded commodity. The London Metal Exchange sets it price daily. Producers are price takers and cannot pass costs to consumers as in more differentiated markets. As a result, domestic producers are particularly at risk of "carbon leakage," the loss of competitive position relative to foreign suppliers. Following the introduction of the EU's own carbon trading system the European primary aluminum industry suffered significant losses. Despite provisions intended to reduce carbon leakage, European production was reduced by as much as 40 percent according to some estimates. Eurometaux 2015. 
passed nation-wide carbon cap-and-trade legislation in 2009, Pittsburgh-based producer Alcoa Corporation was among its most vocal proponents. ${ }^{2}$

Alcoa's support for cap-and-trade was more than a simple public relations campaign. Alcoa was a founding member of the US Climate Action Partnership (US CAP), an industry group counting BP, Duke Energy, and Caterpillar among its members. The Waxman-Markey bill passed by the House of Representatives was modeled directly on draft legislation published by US CAP. ${ }^{3}$ Outside of US CAP numerous other firms, including electric utilities themselves, provided public support for climate action. Louisiana-based electric utility Entergy called the proposed cap-and-trade system "a major step forward in solving the biggest challenge of our time" and lobbied for its passage. ${ }^{4}$ These and other firms played a major role in pushing for, and shaping, US cap-and-trade legislation.

To be sure, private sector opposition remains. In fact a key feature of industry's response to climate change policy has been its divisiveness within industries. While BP promoted the 2009 cap-and-trade bill as a member of US CAP, Exxon Mobil denied the threat of climate change until a change in leadership brought grudging acknowledgment in 2014. While Alcoa has long advocated effective climate change policy, one of its main US competitors, Noranda Aluminum, publicly threatened to relocate to Mexico if Waxman-Markey became law and lobbied lawmakers to oppose. ${ }^{5}$ Major agricultural groups including the National Farmers Union supported the cap-and-trade bill while the American Farm Bureau and others lobbied against it. ${ }^{6}$

Why do some firms support costly legislation while others continue to oppose? How does globalization shape firm incentives to support domestic regulation? I argue that competition for market share drives firms to support climate change policies in order to impose costs on domestic competitors. While policies to combat climate change impose costs on all firms in the economy, these costs vary across firms even within industry. It follows that while climate change policy increases costs across the board, it also leads to shifts in market share that benefit those firms with relatively low adjustment costs. If these shifts in market share are large, they may compensate for the policy's direct costs, creating incentive for lowadjustment-cost firms to lobby in favor. This has distinct implications for the strategic calculus of firms exposed to the global economy.

There are several reasons that domestic competitors might anticipate dramatically different adjustment costs from regulation. First, cost advantages may arise as a result

2. At the time, the US imported around 60 percent of its domestically used primary aluminum. Aluminum Association 2009.

3. US CAP 2009.

4. Entergy Corporation 2009.

5. Marilyn Taylor, "Blunt's Visit Brings Up Health Care Issues," Joplin Independent, 20 August 2009.

6. These divisions within the agricultural lobby led one commentator to remark that the legislation had "succeeded in doing something neither the nation's environmental groups or [sic] the Bush administration could do: Create fault lines in the farm bloc.” Laws 2009, 1. 
of variation in firms' ex ante capital stock. Increasing the energy efficiency of production becomes more expensive the older a firm's machinery and equipment currently in use. ${ }^{7}$ Second, asymmetric adjustment costs might reflect prior investments related to energy efficiency or long-term access to clean energy. ${ }^{8}$ Third, adjustment costs can vary with the location of firms' production facilities. Within the United States, regions vary in the mix of fuels commonly used for electricity generation. Those regions that rely more intensively on coal tend to emit high levels of greenhouse gases. The costs of emissions reduction in these areas are anticipated to be higher relative to regions that rely on cleaner sources of fuel. ${ }^{9}$

From here on I refer to any firm-specific advantage in adjusting to the costs of mitigation policies as green capital. To study how green capital affects firm behavior I develop a game theoretic model in which two firms have the opportunity to participate in the political process prior to engaging in market competition. The model consists of two phases. In the policy phase firms offer campaign contributions to a single policymaker who subsequently chooses a level of regulation for the economy. ${ }^{10}$ In the competition phase each firm selects a level of output and sells its product at the resulting market price. Tying the two phases together is the relationship between the level of regulation in the economy and firms' (relative) marginal costs. Marginal costs are increasing in the level of regulation in the economy. Yet the sensitivity of marginal costs to regulation depends upon firm-specific green capital: firms with high green capital anticipate lower marginal adjustment costs than their competitors.

I first analyze equilibrium behavior in a benchmark model in which only domestic firms compete. I provide conditions under which firms facing low adjustment costs lobby in favor of climate change legislation. The degree of heterogeneity in adjustment costs is key: supportive lobbying will emerge only where firms hold a significant cost advantage over the competition. I also demonstrate the model's plausibility by providing empirical evidence consistent with the core argument that competitive concerns drive lobbying on climate change legislation. I analyze newly collected data

7. Later, I detail the case of Xcel energy which discovered the advantages of its comparatively new capital stock relative to older competitors and subsequently embraced the cause of climate change regulation.

8. Such is the case for Alcoa which has secured long-term contracts supplying nearly 70 percent of its aluminum-smelting operations with clean hydroelectric power. Alcoa Corporation 2017. By contrast, Noranda Aluminum's single aluminum-smelting facility in New Madrid, MO, relied for its energy needs on a long-term contract with Ameren, Missouri's largest electric utility, which in 2009 generated electricity almost exclusively using coal-fired plants. Ameren Corporation 2011; Noranda Aluminum Holding Corporation 2009.

9. These anticipated costs affect not only utility companies themselves, but are also passed on to industrial consumers of electricity including manufacturers and other energy-intensive industries. Such firms often have little discretion over the location of their production facilities for exogenous reasons. For example, high costs of transporting empty containers imply that producers of consumer goods containers must locate production facilities in close proximity to large buyers. Silgan Holdings Inc. 2017.

10. I focus here on broad-based, nationally mandated regulation, in contrast to narrower initiatives arising from the private sector itself or from delegation of regulatory functions to private actors as in Green 2013. 
on firm lobbying in favor of the American Clean Energy and Security Act, a nationwide cap-and-trade bill passed by the US House of Representatives in 2009. Using fine-grained geographic proxies for anticipated adjustment costs, I find that firms whose competitors are expected to bear high costs are significantly more likely to lobby in favor.

I next consider firms' incentives to lobby in favor of climate change regulation in an open economy. Firms facing import pressure - or engaged in export abroad—must compete with foreign firms not subject to the domestic regulatory environment. Yet gains in competitiveness relative to domestic competitors may compensate for losses relative to foreign firms. Firm preferences reflect not only the market share of foreign competitors, but also the distribution of green capital among domestic competitors. I also show that firms engaged in global value chains may gain from climate change regulation if it increases the cost of intermediate goods to domestically sourced competitors. Statistical tests support the argument that multinationals active in final goods production exhibit greater preference intensity - that is, are more likely to lobby in favor of climate change regulation-than their counterparts engaged in other stages of production.

The arguments advanced here amend two dominant approaches to the study of firms and climate change politics. Most closely related, a series of papers explore firms' competitive incentives to embrace pro-environmental lobbying. Vogel argues that early adopters of environmental standards export these standards to trade partners through restrictions on market access benefiting firms in front-runner countries at the expense of laggard-country competitors. ${ }^{11}$ Genovese and Tvinnereim and Genovese emphasize the direct gains accruing from the overallocation of permits to some firms under carbon trading schemes, permits which can be subsequently sold for windfall profits. ${ }^{12}$ My argument is substantially more general than these earlier accounts: it establishes that strategic incentives to support climate change regulation can occur in nearly any regulatory setting. The emergence of these incentives does not rely on the presence or absence of asymmetries in how industries are regulated nor on cross-national variation in the adoption of climate change regulation. Instead, variation in firms' anticipated regulatory costs alone is sufficient to generate support.

A second approach to the study of firms and climate change politics emphasizes the role of open borders in shaping firm preferences. Where regulation remains lax, domestic firms abroad may fear greater competition from foreign firms operating

11. Vogel 1997. This argument builds on earlier work by Porter and others which argues that stricter environmental regulations may benefit firms in front-runner countries since these early adopters will have a competitive advantage down the line when other countries inevitably follow suit. See ListonHeyes and Heyes 1999; Nehrt 1998; Porter and van der Linde 1995a, b.

12. Genovese and Tvinnereim 2018; Genovese 2018. Intra-industry variation in support or opposition to climate change regulation has also been explored at the individual level. For example, see Bechtel, Genovese, and Scheve 2019 which explores how individually held social norms may moderate concerns about industry-specific adjustment costs, leading to intra-industry variation in public support. 
in comparatively low-cost environments. ${ }^{13}$ Another widely held view is that multinational corporations (MNCs) may support climate change regulation to promote compatibility of national policy initiatives. ${ }^{14}$ The theory and supporting evidence I describe provide a very different account. First, even in the presence of foreign competition, firm preferences are determined in part by their position with respect to domestic competitors. Second, multinational firms may in fact gain from variation in national regulatory regimes, an alternative explanation for $\mathrm{MNC}$ preferences which is supported by the descriptive analysis.

In addition to these substantive contributions, this work builds on the now-standard approach of incorporating insights from the field of industrial organization into models of international trade. ${ }^{15}$ The results of this "new" New Trade Theory have been fruitfully applied to the study of firm political preferences in a growing number of papers. ${ }^{16}$ In a similar vein this work draws on the insights of industrial organization regarding regulation's competitive effects within industry. This argument has most widely been made where regulation acts as a barrier to entry. ${ }^{17}$ Yet as in my current work others have studied the distributional effects of regulation that affect firm-variable costs. ${ }^{18}$

Incorporating these insights into an open economy setting highlights how domestic competition mediates firm preferences for international cooperation. Thus far the dominant approach within international political economy has been to derive firm preferences by exploring their competitive position relative to foreign, rather than domestic, competitors. ${ }^{19}$ Growing scholarly attention to within-industry variation in firms' competitive positions suggests that this may overlook important nuances in firm preferences, arising from strategic and competitive considerations within the domestic market. While firms compete simultaneously with foreign and domestic competitors, domestic competitors will often be the more salient category which suggests that regulation's implications for these firms will matter even within an open economy setting. Calculations about gains and losses relative to these distinct groupings combine to shape firm preferences for international cooperation.

\section{The Asymmetric Costs of Climate Change Regulation}

To elaborate on the argument, I provide descriptive analysis of firms' political participation in climate change policymaking and variation in expected adjustment costs. I focus in particular on the case of the American Clean Energy and Security Act

13. Aklin 2016; Kleemann and Abdulai 2011; Peters et al. 2011.

14. Garcia-Johnson 2000.

15. Melitz 2003.

16. Chaney 2008; Kim 2017; Osgood et al. 2017.

17. Rogerson 1984; Stigler 1971.

18. Michaelis 1994; Salop and Scheffman 1983, 1987.

19. Lake 2009. 
(ACES) of 2009, the closest the US Congress has come to enacting comprehensive climate change legislation. Passed by the US House of Representatives on 26 June 2009 , the ACES called for a nation-wide "cap-and-trade" system to reduce emissions of carbon dioxide and other greenhouse gases. The patterns that emerge from this analysis provide support for the empirical plausibility of the formal model, and insight into the mechanisms of my argument. ${ }^{20}$

The ACES originated in the House Committee on Energy and Commerce early in 2009 under the leadership of Representative Henry Waxman (D-CA), then chairman of the committee, and Representative Ed Markey (D-MA). The committee remained active throughout 2009 and 2010, holding a series of hearings on the design and implementation of a national carbon cap-and-trade system. Throughout, its membership was strictly partisan in its approach: voting for the bill took place along party lines with Republican members proposing over 400 amendments over the course of the year in an attempt to slow legislative progress. Campaign contributions to Democratic versus Republican members of the committee during this period thus provide a useful proxy for firms' support or opposition to the cap-and-trade bill. ${ }^{21}$

Figure 1 depicts the amount and proportion of campaign contributions directed toward each party for all Fortune 500 companies. ${ }^{22}$ Each point corresponds to a single firm, scaled by the amount of the firm's total contributions. Vertical placement indicates the sector each firm is a member of while horizontal placement indicates the proportion of contributions directed toward Democratic (that is pro-climate legislation) candidates. While a number of firms give contributions to members of both parties and so fall within the interior of the plot, the vast majority of firms provide contributions to only a single political party. In fact a key feature of this giving is the variation within sector of firms' preferred political party. Nearly all sectors appear strongly bimodal with a number of firms supporting only Republican candidates and a similar number supporting only Democratic candidates. Combined with the anecdotal data I noted in the introduction, these contributions suggest significant variation within industry in firms' position taking with respect to climate change legislation.

My core argument is that this variation in firms' position taking can be explained by intra-industry competition between firms. The following example illustrates the

20. The bill stalled the following year in the Senate following an upswell in public opposition from the Republican base though obtaining sufficient support from industry actors was widely viewed as a crucial precondition to legislative success. See Lizza 2010; Skocpol 2013. Appendix C2 provides further discussion.

21. Partisanship was similarly strong though not monolithic in the Senate rendering contributions in that body a less useful proxy. The Senate does yield one useful (qualitative) example of the scale of financial rewards associated with position taking on climate legislation. When Senator Lindsay Graham (R-SC) joined forces with Senators John Kerry (D-MA) and Joe Lieberman (D-CT) to spearhead the Senate version of a climate bill, he raised USD 49,000 from electric utilities in the first quarter of 2010. In the entirety of the previous year he received no contributions from electric utilities and just USD 14,450 from all industry PACs combined. Lizza 2010.

22. Firm-level contributions are defined here as the sum of individual contributions by executive officers of each firm. Bonica 2017. 
mechanism. In 2004 Colorado voters approved a state-wide renewable energy portfolio standard despite opposition from local utility companies, including Colorado's largest provider, Xcel Energy. Despite this initial opposition, Xcel quickly discovered that the renewable energy standard placed a far higher burden on its biggest competitors-older natural gas plants-whose facilities were less efficient because of age. Ordinarily the natural gas plants benefited from their older facilities, having paid off capital costs and bidding electricity prices low as a result.

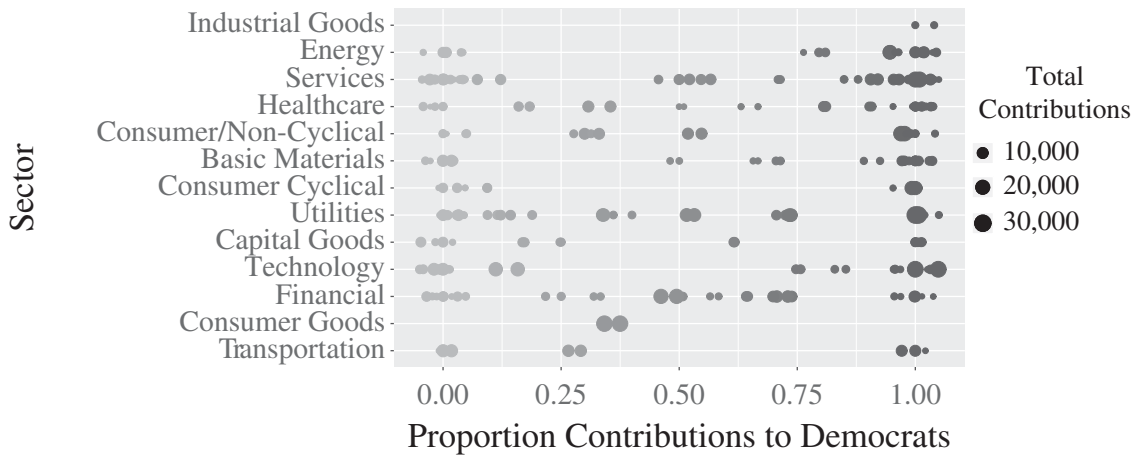

Notes: Contributions by Fortune 500 executives to members of House Energy and Commerce Committee during 111th Congress. Contributions aggregated to corporation and plotted by sector. Size corresponds to total corporate giving. Horizontal placement corresponds to proportion Democratic (pro cap-and-trade) contributions. Contribution data from Bonica 2017.

FIGURE 1. Campaign contributions to members of house energy and commerce committee

The renewable energy standard reversed this advantage: Xcel gained market share while meeting its own regulatory burden with little effort. Unsurprisingly, Xcel subsequently reversed its political strategy, joining the successful campaign for an even stricter renewable energy standard in $2007 .{ }^{23}$ Generalizing from this example about which firms will enjoy a cost advantage relative to their competition is no easy task. Adjustment to climate change regulation depends on a confluence of factors, the most salient of which may vary from one industry to another. Nonetheless publicly available data make clear the variation among firms in their likely costs of adjustment to any new climate change regime.

Figure 2 depicts within-industry variation on a number of dimensions likely to have an impact on climate change adjustment costs. The top two panels plot the mean versus standard deviation of (logged) annual investment in property, plant and equipment (left panel), and existing capital stocks (right panel) by industry. Manufacturing industries, on average disproportionately affected by climate 

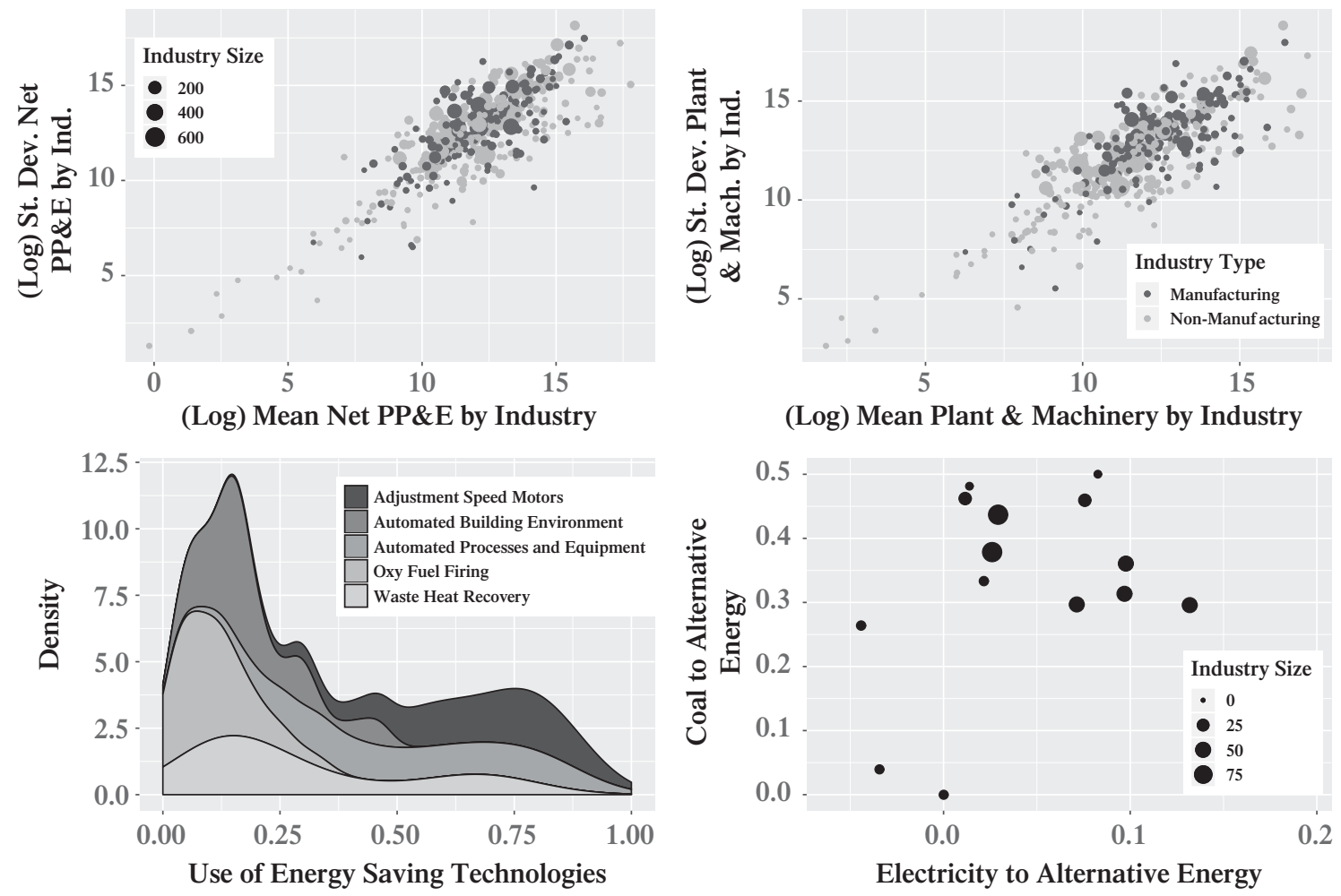

Notes: Top left (right) panel depicts mean versus standard deviation of net property, plant, and equipment (plant and machinery) by industry. Size corresponds to number of incumbent firms represented in an industry with manufacturing industries depicted in black and nonmanufacturing in gray. Lower-left panel depicts density of industries by proportion incumbents employing various energy-saving technologies. Lower-right panel plots proportion incumbents with ability to switch from electricity and coal to alternative energy sources. Points correspond to industries with size reflecting number of incumbents reporting.

FIGURE 2. Variation in firm investments and adjustment costs 
change regulation due to their high energy usage, are depicted in black while nonmanufacturing industries are depicted in gray. Across industries considerable variation exists in the mean level of both investment and existing capital stocks. Yet both plots also depict significant variation among firms within industry: both display a near linear relationship between mean investment (capital stocks) and the corresponding industry standard deviation. Both variables matter for firm adjustment costs because existing capital stocks may require retrofitting or replacement to enhance energy efficiency while more recent investments-as in the case of Xcel -may indicate higher levels of ex ante preparedness.

The bottom two panels of Figure 2 speak directly to variation within industry in firms' preparedness for climate change regulation. The left-hand panel depicts the density (across industries) of the proportion of firms employing several examples of energy-saving technology. For example, within the modal industry only around 15 percent of firms report employing automated technologies to control the building-wide environment, though in some industries the proportion of firms employing these technologies may be 50 percent or greater, again suggesting significant variation in firms' existing investments in energy efficiency. The right-hand panel plots the proportion of firms by industry who report the ability to switch from electricity to alternative energy sources versus the proportion of firms in the same industry with the ability to switch from coal to alternative energy sources. While a number of industries cluster at 0 -indicating that no incumbent firms report the ability to fuel switch on either dimension - within the majority of industries a positive though small fraction of firms report the ability to switch energy sources given appropriate incentives.

Figure 3 highlights one last source of variation in adjustment costs that firms often have little control over. The left panel of Figure 3 displays the spatial distribution of (logged) per capita carbon intensity from electricity generation across the fifty states with darker states corresponding to greater carbon intensity. ${ }^{24}$ The right-hand panel of Figure 3 depicts the density of carbon emissions per capita from electricity generation, weighted by the number of firms operating in each state. The figure makes clear the variation in energy cost environment across firms. The modal firm is located in a relatively low carbon-intensive state but a large proportion of firms nonetheless operate in more emission-heavy environments. ${ }^{25}$

24. Data on energy-related carbon emissions come from the US Energy Information Administration. State population data are taken from the US census. Carbon intensity of electricity generation is closely related to the presence of coal reserves within state, with Wyoming, West Virginia, and Kentucky-as well as their neighboring states-displaying particularly high emissions. Figure 10 in Appendix B1 depicts the spatial distribution of (logged) coal reserves by state. Comparison with the left panel of Figure 3 reveals striking similarities. Figure 11 depicts industrial coal usage by state-scaled by industrial GDP - as well as the average price of coal for industrial end users, which exhibits a similar pattern.

25. This asymmetry in adjustment costs was well noted at the time. One account details a meeting between Senators Joe Liberman (D-CT) and Evan Bayh (D-IN) in which Bayh appeared with a map of the United States shaded by the proportion of electricity derived from coal in each state. According to 


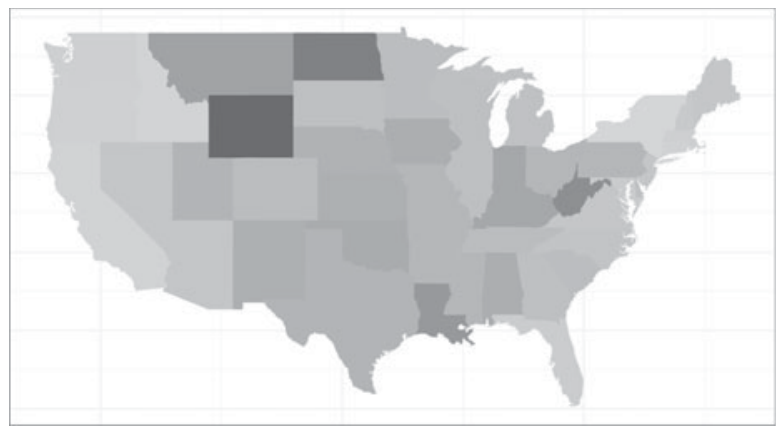

State-Level Carbon Emissions per Capita

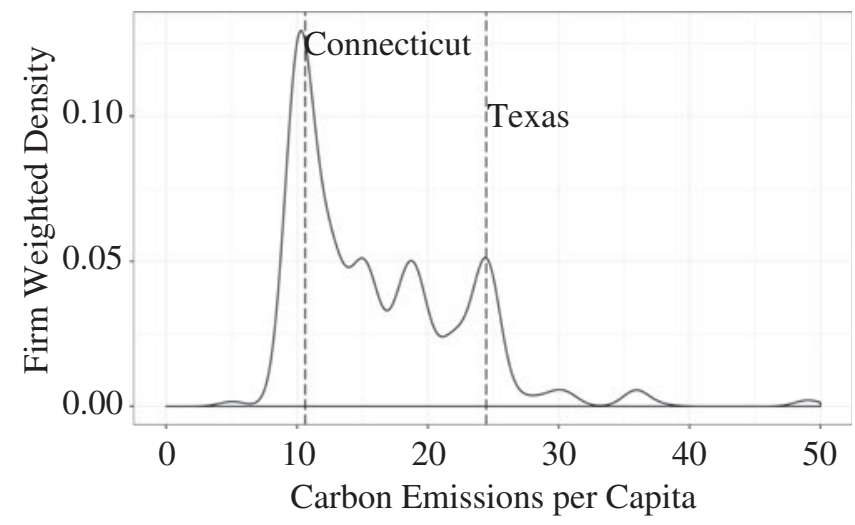

Notes: Panel (a) depicts the log of carbon emissions from electricity generation (measured in million metric tons) per capita, by US state. Lighter colors indicate more effcient electricity production. Darker states represent more carbon-intensive electricity production. Panel (b) depicts the firm-weighted density of carbon emissions from electricity generation per capita for US states.

FIGURE 3. Carbon emissions per capita from electricity generation 
Finally I provide direct evidence of the variation in firms' anticipated exposure to climate change legislation. To do so I estimate an event study of firm-level abnormal returns following passage of the ACES. Event studies are widely employed in the finance literature to estimate the impact of economic or financial events on the profitability of individual firms. The core idea of the event study framework is to predict firm profits immediately following the event, employing data from a period of time immediately preceding the event. The difference between observed and predicted profits is then interpreted as the abnormal return, potentially attributable to the event under study. The probability of observing this abnormal return by random chance can then be calculated employing an estimate of the variance of firm-level abnormal returns.

To predict abnormal returns I employ a market model, a standard approach in the finance literature, in which a predicted abnormal return is generated for each firm by regressing that firm's returns prior to the event on a chosen market index and then predicting returns based on the resulting coefficient estimates. ${ }^{26}$ As my index I employ the Dow Jones Industrial Average and estimate the model employing data on the twenty-five days prior to and ten days following passage of H.R.2454 (the US Clean Energy and Security Act). If market actors anticipated a successful outcome in the days immediately prior to passage then including the observed returns from these days could bias the results. For this reason I exclude the five days prior to treatment from my definition of the pre-event window. ${ }^{27}$

Figure 4 plots the estimated abnormal returns to all publicly traded manufacturing firms following the passage of the ACES. The abnormal returns, aggregated across firms and across industries, are jointly significant and negative on average. This is consistent with the predicted overall economic costs of climate change regulation. Yet within industry there is much variation in investor perceptions of the legislation's firm-level impact. Most importantly, while the average abnormal return for nearly all industries is negative as expected, in many industries the abnormal returns to a minority of firms are estimated to be positive, suggesting that some firms are expected to gain in profitability following the imposition of costly climate change legislation.

In the next section I develop a formal model that connects the variation in firms' anticipated adjustment costs detailed here with support for climate change legislation.

\section{Model}

Let there be two firms $i=1,2$ and a policymaker. In the initial phase, firms attempt to influence the policymaker's choice of a (unidimensional) regulatory regime, $r \in[0, R]$

an aide present at the meeting: "Every time Senator Lieberman would open his mouth [to ask for Bayh's support], Bayh would show him the map." Lizza 2010, 5.

26. Kothari and Warner 2007.

27. Appendix B2 includes additional description of the event study analysis including full specification of the market model and a description of the data employed. 

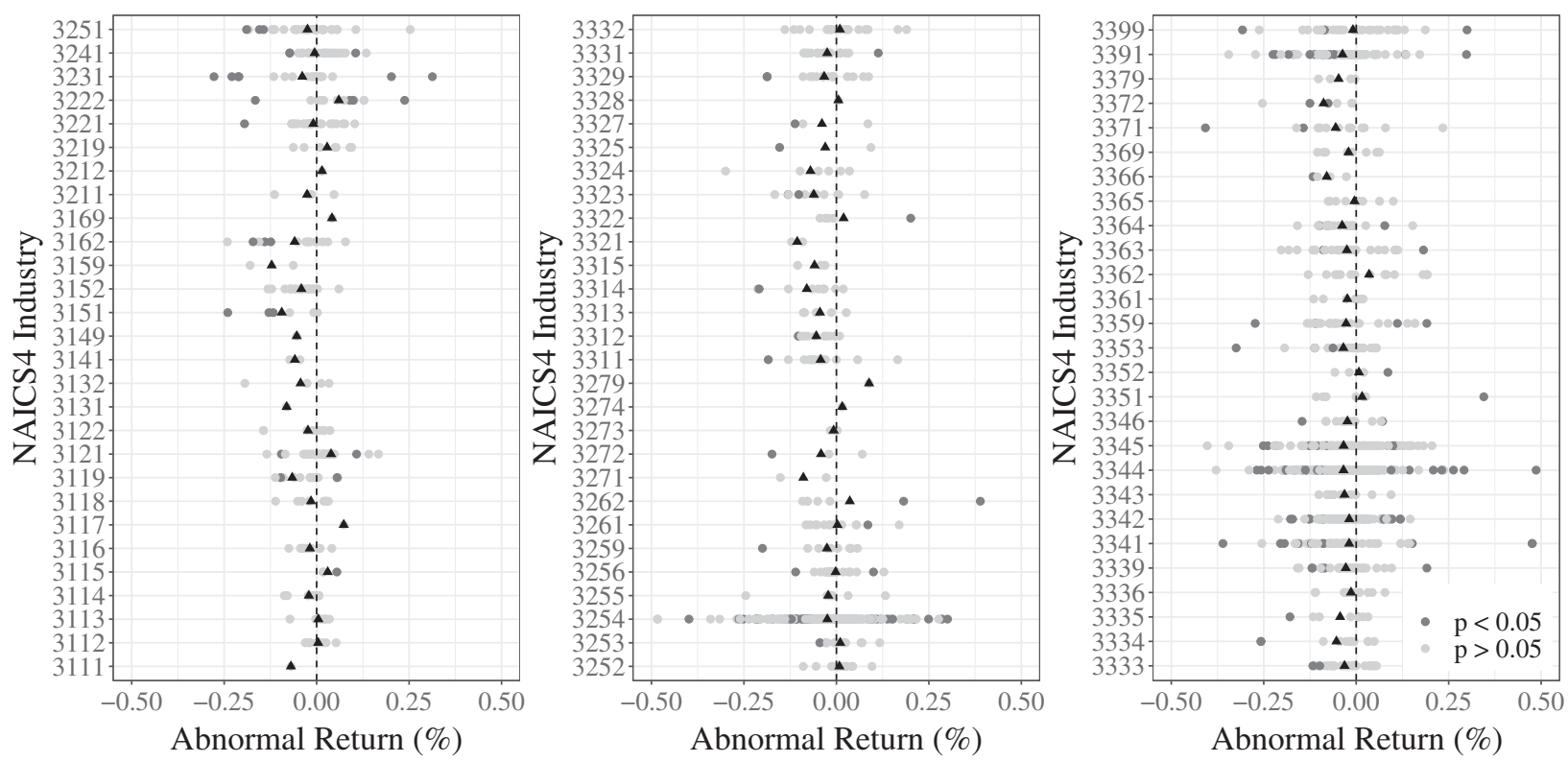

Notes: Firm-level abnormal returns for all publicly traded manufacturers following House passage of H.R.2454, the US Clean Energy and Security Act on 29 June 2009. Abnormal returns plotted by four-digit NAICS industry with estimates statistically significant at the 0.05 level in dark gray and industry average abnormal return depicted in black.

FIGURE 4. Abnormal returns to manufacturing industries following passage of H.R.2454 
where $R>0 .{ }^{28}$ To do so, firms simultaneously announce contribution schedules, $s_{i}:[0, R] \rightarrow \mathbb{R}^{+}$for $i=1,2$. Each contribution schedule is a function, mapping every possible level of regulation to a corresponding non-negative campaign contribution, which the firm commits to providing in case that level of regulation is adopted. Contribution schedules are binding so firms cannot renege on their promises once they've been announced. $^{29}$

Following firms' announcements of their contribution schedules, the policymaker selects a level of regulation. I assume that the policymaker cares about both the policy outcome and her realized campaign contributions. In particular her ideal policy is given by $r^{P M} \in[0, R] .{ }^{30}$ While I take this ideal point to be exogenous, it can be interpreted as the social value of regulation, weighted by the policymaker's beliefs about the dangers of climate change. The policymaker values campaign contributions and is indifferent to their source. The policymaker's objective function is:

$$
g\left(r \mid s_{1}(\cdot), s_{2}(\cdot), r^{P M}\right)=-\lambda\left(r^{P M}-r\right)^{2}+(1-\lambda)\left(s_{1}(r)+s_{2}(r)\right)
$$

where $\lambda \in[0,1]$ is the weight the policymaker attaches to her own policy preferences and $(1-\lambda)$ is the weight she attaches to campaign contributions.

In the competition phase of the game firms produce a single homogeneous good that they sell at an endogenously determined market price. The phase begins with firms simultaneously selecting output levels $q_{i} \in \mathbb{R}^{+}$for $i=1$, 2. Price is decreasing in aggregate output according to the inverse demand function:

$$
p\left(q_{i}, q_{j}\right)= \begin{cases}\alpha-q_{i}-q_{j} & \text { if } q_{i}+q_{j} \leq \alpha \\ 0 & \text { if } q_{i}+q_{j}>\alpha\end{cases}
$$

for some $\alpha>0$. Throughout I assume that $\alpha$ is "large" in the sense that for even the strictest regulatory regime, it remains optimal for both firms to produce positive output. ${ }^{31}$

Firms have constant, asymmetric marginal costs reflecting the level of regulation in the economy, $r$, and a firm-specific parameter, $F_{i}$, representing firm $i$ 's level of "green capital." Green capital can be interpreted as any geographic or firm-level characteristic that provides advantage in the case that more stringent regulation is passed. For

28. Assuming an upper bound to the regulatory space corresponds to the idea that there are natural technological and policy limits to what can be accomplished via government regulation. Identical results hold - assuming the regulatory space is unbounded from above-so the assumption is without loss of generality and facilitates clarity of the exposition that follows.

29. Here political participation takes the form of campaign contributions. The model is also consistent with lobbying as information provision in that this can be interpreted as a subsidy to the policymaker's legislative resources.

30. In Appendix C2 I microfound the policymaker's ideal level of regulation in the welfare of a representative voter, thus balancing the desire for climate change policy against the economic externalities of regulation. Similarly the role of nongovernmental organizations could easily be incorporated as an additional source of political contributions. Hadden 2015; Hadden and Jasny 2019.

31. Formally this requires $\alpha>R\left(\frac{2}{F_{j}}-\frac{1}{F_{i}}\right)$ where $j$ is assumed to be the high-adjustment-cost firm. 
example, a low $F_{i}$ may reflect the location of production facilities in regions expected to be hardest hit by legislation or may reflect obstacles to increasing the energy efficiency of a firm's capital stock. Higher values of $F_{i}$ indicate that a firm holds a competitive advantage in coping with climate change regulation. Marginal costs are $c\left(F_{i}, r\right)=\frac{r}{F_{i}}{ }^{32}$

For both firms costs are increasing in $r$ and decreasing in $F_{i}$. The marginal cost of regulation, $r$, is strictly decreasing in green capital, $F_{i}$. These assumptions are key for the results of the model. They ensure that firms holding high levels of green capital face lower adjustment costs than their high-cost competitors. Each firm's profits are defined by total revenue less total costs, or:

$$
\pi_{i}\left(q_{i}, q_{j}, F_{i}\right)= \begin{cases}q_{i}\left[\alpha-q_{i}-q_{j}-c\left(F_{i}, r\right)\right] & \text { if } q_{i}+q_{j} \leq \alpha \\ -q_{i} c\left(F_{i}, r\right) & \text { if } q_{i}+q_{j}>\alpha\end{cases}
$$

for $i=1,2$. I assume that firms seek to maximize profits less the cost of their equilibrium campaign contribution. I assume that there are some (unmodeled) barriers to entry which prevent profits from being dissipated. ${ }^{33}$

Finally, let $\gamma_{i}=\frac{1}{F_{j}}-\frac{2}{F_{i}}$ and vice versa for firm $j$. The meaning of this notation will become clear in the analysis. The following technical assumption ensures that the policymaker's utility is strictly concave, ensuring the existence of a unique solution:

$$
\lambda>\frac{\gamma_{i}^{2}+\gamma_{j}^{2}}{9+\gamma_{i}^{2}+\gamma_{j}^{2}}
$$

It it straightforward to confirm that the lower bound on $\lambda$ lies between 0 and 1 and is thus well defined. Substantively the assumption implies that the policymaker places relatively high weight on his own preferences relative to those of the firms. Alternatively this may be interpreted as implying that each individual firm has only a marginal impact on policymaking, an empirical point consistent with findings in the literature on firm lobbying. ${ }^{34}$

In the analysis I restrict attention to Truthful (Subgame Perfect) Nash Equilibria. ${ }^{35}$ A firm's contribution schedule is said to be truthful relative to equilibrium policy $r^{*}$ if one of the following conditions applies for every policy alternative, $r^{\prime}$ : (1) the promised contribution, $s_{i}\left(r^{\prime}\right)$, leaves the firm with the same net utility if either $r^{*}$ or $r^{\prime}$ is selected, or (2) the promised contribution is exactly 0 . That is, if firm $i$ 's contribution schedule is truthful, then it offers for each alternative exactly its value for

32. Results remain similar assuming a more general functional form. The formulation of adjustment costs can capture either costs arising directly from the production and sale of electricity (as in the case of electric utilities or other energy providers) or increases in the cost of inputs (particularly electricity) in the case of manufacturing or other sectors. The requirement is simply that the variable costs associated with production increase differentially across firms with the level of climate regulation. In Appendix C3 I consider the strategic decision of firms to invest in green capital, endogenizing the marginal adjustment costs of regulation.

33. Oster 1982.

34. Kang 2015.

35. Bernheim and Whinston 1986. 
switching from $r^{*}$ to that alternative, provided this value is non-negative. Otherwise the firm offers 0. A Truthful Nash Equilibrium is a Nash Equilibrium in which all firms employ truthful strategies. ${ }^{36}$

\section{Green Lobbying in a Closed Economy}

The focus of the following analysis is the emergence of firm lobbying in favor of climate change legislation. I first characterize optimal behavior at each stage of the game. Conditions for the emergence of green lobbying follow naturally from this analysis.

\section{Equilibrium Characterization}

The game is solved via backwards induction, beginning in the market competition stage. Firm $i$ maximizes profits, taking into account firm $j$ 's output $q_{j}$. The best response function maps firm $j$ 's output to firm $i$ 's optimal choice, $\tilde{q}_{i}\left(q_{j}\right)$. Equilibrium outputs are determined by the intersection of the best response functions for the two firms. Firm $i$ 's equilibrium output is

$$
q_{i}^{*}=\max \left\{\frac{1}{3}\left(\alpha+r^{*} \gamma_{i}\right), 0\right\}
$$

where, as defined earlier, $\gamma_{i}=\frac{1}{F_{j}}-\frac{2}{F_{i}}$. Note that given the assumption that $\alpha$ is large, $q_{i}^{*}>0$ for any feasible regulatory level.

We can now interpret $\gamma_{i}$ substantively as a measure of the distance between the two firms' marginal cost of regulation or firm $i$ 's relative efficiency. It is central to our analysis. For any positive level of regulation, firm $i$ 's output is increasing in its relative efficiency. At the same time, the impact of $\gamma_{i}$ on equilibrium output is moderated by the level of regulation. For low levels of regulation, differences in adjustment costs matter little. For higher levels of regulation, differences in adjustment cost will lead to significant divergence in firm outputs.

Firm profits depend both on total output and on production costs. Equilibrium profits are

$$
\pi_{i}\left(q_{i}^{*}\right)=\frac{1}{9}\left(\alpha+r \gamma_{i}\right)^{2}
$$

It is immediate from this expression that firm $i$ 's profits are increasing in $r$ when $\gamma_{i}>0$. This requires that firm $i$ hold twice the level of green capital as firm $j, F_{i}>2 F_{j}$. If firm $i$

36. This assumption can be relaxed significantly. See Grossman and Helpman 2001. Note that the initial phase follows Bernheim and Whinston 1986 as well as Grossman and Helpman 1992, 2001 in modeling lobbying as a first-price menu auction. In the second phase firms compete by selecting quantities as in models of Cournot competition. The main results are robust to the assumption that firms engage instead in price (Bertrand) competition. 
holds only a slight advantage over his competitor, or if it is his competitor who holds the advantage, firm i's profits are decreasing in $r$. Note that if $\gamma_{i}>0$, it must be that $\gamma_{j}<0$. Profits can be increasing in regulation for at most one firm. ${ }^{37}$

Now that we have characterized equilibrium behavior in the market competition phase of the game we can proceed to analyze optimal behavior during the policymaking phase. In selecting a level of regulation, the policymaker takes each firm's contribution schedule, $s_{i}(\cdot)$ and $s_{j}(\cdot)$, as fixed and chooses the optimal $r$, setting the marginal benefit of increasing regulation equal to its marginal cost. Rearranging the policymaker's first-order condition yields

$$
r^{*}=r^{P M}+\frac{1-\lambda}{2 \lambda}\left(\left.\frac{d s_{1}(r)}{d r}\right|_{r^{*}}+\left.\frac{d s_{2}\left(r^{*}\right)}{d r}\right|_{r^{*}}\right)
$$

This expression makes clear that equilibrium regulation depends not on the absolute level of political contributions but rather the marginal contribution from each firm. Recall that, given the assumption of truthful contribution schedules, firm contributions are such that they receive the same level of utility given policy choice $r^{*}$ as for any $r^{\prime} \neq r^{*}$. This implies that any change in profits brought about by a shift in policy must be exactly offset by a corresponding change in the firm's expenditure on lobbying. Since each firm's marginal value for money is constant (and equal to 1) this in turn implies that any change in profits must be offset by an identical and opposite change in the firm's contribution. For small deviations from the equilibrium policy, it must then be the case that firms' marginal contributions in equilibrium are exactly equal to their marginal change in profits. Evaluating the required derivatives and rearranging (5) yields the equilibrium policy. Recalling that the policy must lie in the interval $[0, R]$, the equilibrium policy is

$$
r^{*}=\min \left\{\max \left\{\frac{r^{P M}+\alpha \beta\left(\gamma_{i}+\gamma_{j}\right)}{1-\beta\left(\gamma_{i}^{2}+\gamma_{j}^{2}\right)}, 0\right\}, R\right\}
$$

where $\beta \equiv \frac{1}{9} \cdot \frac{1-\lambda}{\lambda}$ is a measure of the weight the policymaker assigns to campaign contributions versus her own policy preferences. Assumption A1 ensures that the derived expression for $r^{*}$ is a global maximum of the policymaker's utility on the feasible set of policies. Note that $\gamma_{i}+\gamma_{j}=-\left(\frac{1}{F_{i}}+\frac{1}{F_{j}}\right)$, or the marginal cost of regulation for the economy as a whole. Thus in the case of an interior solution, the numerator in equation (9) is strictly decreasing in the average marginal costs of regulation. In contrast, the denominator is decreasing in the distance between firms' adjustment costs. Equilibrium regulation then depends both on average and relative adjustment costs.

Finally we consider firms' optimal contribution schedules. Recall that in any Truthful Nash Equilibrium firms' contribution schedules must be truthful relative

37. In the case of $N$ firms this no longer holds. See Appendix $\mathrm{C} 4$ for analysis of the more general case in which $N$ firms compete in the same industry. 
to the policy, $r^{*}$. This implies that contribution schedules will take the following form:

$$
s_{i}(r)=\pi_{i}(r)-\pi_{i}\left(r^{*}\right)+s_{i}\left(r^{*}\right)
$$

The schedule is completely pinned down by firm $i$ 's equilibrium contribution, $s_{i}\left(r^{*}\right)$. All that remains then is to calculate this contribution. We have already characterized equilibrium regulation, $r^{*}$. Using a similar approach we can characterize the equilibrium outcome if firm $i$ chooses not to contribute, $r^{j}$. If firm $i$ chooses not to contribute then the policymaker attains utility $g\left(r^{j}\right)$. Taking into account $i$ 's equilibrium contribution, the policymaker attains utility $g\left(r^{*}\right)$. Given that the policymaker can achieve $g$ $\left(r^{j}\right)$ by ignoring firm $i$ and choosing $r^{j}$, it must be that if she chooses $r^{*}$ in equilibrium, she is at least as well off. Firm $i$ never optimally provides a greater contribution than what is strictly required to induce $r^{*}$ thus the equilibrium contribution is that which yields exactly $g\left(r^{j}\right)=g\left(r^{*}\right)$. Plugging firm $j$ 's contribution schedule (defined similarly to (7)) into the policymaker's indifference condition establishes firm $i$ 's equilibrium contribution. Figure 5 depicts the construction of the equilibrium.

Note that this condition pins down the vertical placement of each firm's contribution schedule. Neither firm has an incentive to shift the schedule upward: doing so does not alter the equilibrium policy choice-provided that the marginal contribution remains unchanged-but simply transfers utility from the firm to the policymaker. At the same time neither firm would choose to lower its contribution schedule since doing so would reduce the policymaker's equilibrium utility, yielding a profitable deviation to either of the reservation values $r^{i}$ or $r^{j}$. Proposition 1 summarizes the analysis so far.

Proposition 1. There exists a unique (truthful) subgame perfect equilibrium:

(a) In the final stage of the game, firms $i=1,2$ choose production levels:

$$
q_{i}^{*}=\max \left\{\frac{1}{3}\left(\alpha+r^{*} \gamma_{i}\right), 0\right\}
$$

where $\gamma_{i}=\frac{1}{F_{j}}-\frac{2}{F_{i}}$.

(b) In the policymaking stage, the legislator selects $r^{*} \in[0, R]$ where

$$
r^{*}=\min \left\{\max \left\{\frac{r^{P M}+\alpha \beta\left(\gamma_{i}+\gamma_{j}\right)}{1-\beta\left(\gamma_{i}^{2}+\gamma_{j}^{2}\right)}, 0\right\}, R\right\}
$$

and $\beta=\frac{1}{9} \cdot \frac{1-\lambda}{\lambda}$. 


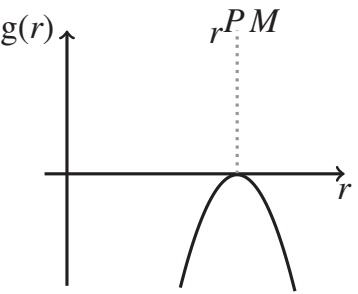

(a)

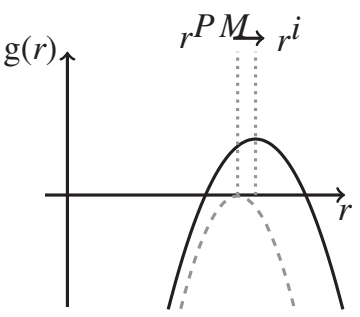

(d)

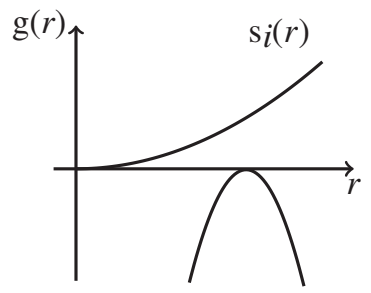

(b)

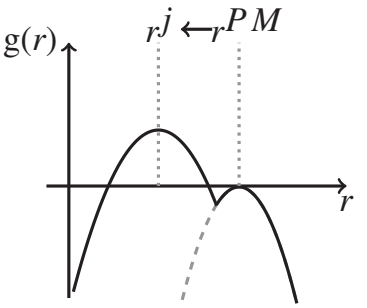

(e)

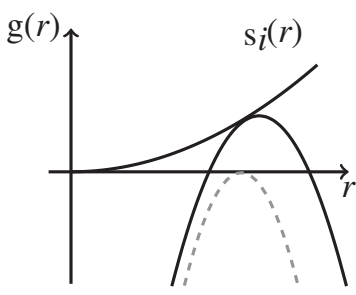

(c)

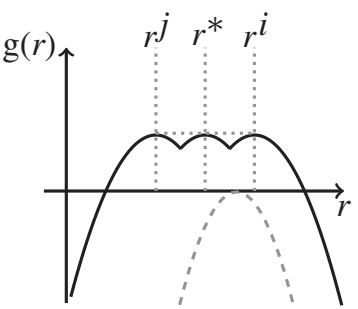

(f)

Notes: Panel (a) depicts a policymaker's preferences independent of firm contributions. Panels (b) and (c) depict the influence of a single (green) firm's contribution schedule on the policymaker's objective function. Contributions from a relatively low-cost firm shift the policymaker's optimal policy choice upward (from $\mathrm{r}^{\mathrm{PM}}$ to $\mathrm{r}^{\mathrm{i}}$ ) as depicted in panel (d). The opposing firm's contributions push the policymaker's optimal choice in the reverse direction (from $\mathrm{r}^{\mathrm{PM}}$ to $\mathrm{r}^{\mathrm{j}}$, panel (e)). Note that $\mathrm{r}^{\mathrm{i}}$ and $\mathrm{r}^{\mathrm{j}}$ act as reservation values for the policymaker. In any equilibrium in which she does not choose either value her utility must weakly exceed that of choosing either. Optimality for each firm implies that this will hold strictly, implying the indifference condition depicted in panel (f).

FIGURE 5. Equilibrium contributions

(c) Prior to the selection of policy, firms announce contribution schedules:

$$
s_{i}(r)=\pi_{i}(r)-\pi_{i}\left(r^{*}\right)+s_{i}\left(r^{*}\right)
$$

where $s_{i}\left(r^{*}\right)=\max \left\{\frac{\lambda}{1-\lambda}\left[\left(r^{P M}-r^{*}\right)^{2}-\left(r^{P M}-r^{j}\right)^{2}\right]+\pi_{j}\left(r^{j}\right)-\pi_{j}\left(r^{*}\right), 0\right\}$.

The proof of Proposition 1 (along with those of all other results) is included in Appendix A. Note that in any equilibrium, firm $i$ offers higher contributions in exchange for policies that improve its welfare, relative to $r^{*}$, and lower contributions (or 0) for policies that leave it worse off. From here on we say that firm $i$ lobbies in favor of regulation if $s_{i}(r)>s_{i}\left(r^{*}\right)$ for all $r \in\left(r^{*}, r^{*}+\epsilon\right)$ and firm $i$ lobbies against regulation if $s_{i}(r)>s_{i}\left(r^{*}\right)$ for all $r \in\left(r^{*}-\epsilon, r^{*}\right)$ for $\epsilon$ greater than 0 . 


\section{The Emergence of Green Lobbying}

My central claim is that relatively low-cost firms lobby in favor of climate change regulation to gain market share at the expense of high-cost competitors. ${ }^{38}$ The next proposition establishes this core result.

Proposition 2. Let $\gamma_{i}>0$. Then firm i lobbies in favor of climate change legislation while $j$ lobbies against.

The intuition behind Proposition 2 is as follows. When $\gamma_{i}$ is greater than 0 , firm $i$ 's profits are strictly increasing in regulation. It is then optimal for firm $i$ to offer greater contributions for higher levels of regulation in equilibrium. Recall that $\gamma_{i}>0$ requires $F_{i}>2 F_{j}$, that is, firm $i$ holds twice the level of green capital as firm $j$. Thus competitive lobbying emerges only if there exists significant heterogeneity in adjustment costs. This reflects the fact that climate change legislation has both a direct and an indirect effect on firm profits. The direct effect of regulation is that of increasing each firm's production cost. The indirect effect is that of shifting market share toward the low-cost firm. If firms are relatively close in terms of their adjustment costs, the former will dominate the latter since the shift in market share must be small. As heterogeneity in adjustment cost grows, the impact of regulation on market share grows, eventually overtaking the direct effect of increasing costs. From here on I refer to any equilibrium in which one firm lobbies in favor of climate change regulation as a "competitive equilibrium."

To provide support for this core result I construct a measure of individual firm support for the ACES by comparing lobbying activity reported under the Federal Lobbying Disclosure Act with public statements of support for H.R.2454. ${ }^{39}$ Firms that both disclose lobbying activity and take a public stance in favor of the climate change bill are coded as supportive. Information on lobbying disclosures is obtained from the Center for Responsive Politics. I construct a measure of anticipated competitor costs by calculating for each firm $i$ (1) the share of competitors within industry $j$ located in zip codes above the median in terms of coal usage in electricity generation and (2) the share of competitors in industry $j$ located in zip codes containing coal reserves. ${ }^{40}$ The resulting measures vary both within industry and within region,

38. In Appendix C1 I generalize this analysis to consider the possibility of firm entry. Regulation may also act as a deterrent to entry, further enhancing incentives for incumbent firms to lobby in favor.

39. Producers and consumers of electricity may differ in the nature of the challenge posed by climate change regulation. Nevertheless I treat these firms symmetrically in the analysis and identify instances of supportive lobbying by both. Figure 12 in Appendix B1 gives the distribution of supportive lobbying across industries and describes the relative prevalence of energy producers versus consumers.

40. Genovese 2019. While the former represents a more direct measure of anticipated adjustment costs, the latter measure has the advantage of being strictly exogenous to the local political environment. Moreover as Figure 10 in Appendix B1 makes clear, the distribution of coal reserves is highly correlated with carbon emissions from electricity generation. Appendix B3 contains additional discussion of the measurement of firm locations and as well as a number of robustness results related to the potential for mismeasurement of production locations. 
reflecting firm i's own location relative to the geographic distribution of its competitors.

The full sample consists of all US-based publicly traded firms whether or not they disclose lobbying activity. ${ }^{41}$ Data on publicly traded firms as well as a number of financial covariates are obtained from the Osiris database. In total I identify 8,216 unique firms representing 276 industries. ${ }^{42}$ Key financial covariates include PROPERTY, PLANT, AND EQUIPMENT, MARKET CAPITAL, PRODUCTIVITY, and MARKET SHARE. ${ }^{43}$ I also include indicator variables that take a value of 1 if a firm is located in a zip code with high anticipated costs, if the firm is a multinational, if the firm is engaged in energy-intensive manufacturing, or if the firm itself is an electricity provider. ${ }^{44}$

Results from logistic regression confirm the existence of a positive and statistically significant relationship between the measures of competitor adjustment costs and a firm's propensity to lobby in favor of cap-and-trade legislation. Figure 6 depicts the marginal effects for an average firm estimated by regressing both measures of competitor costs on supportive lobbying and controlling for a range of firm-level characteristics. The estimated effects are substantively meaningful. Moving from the mean to one standard deviation above the mean for either independent variable increases the probability of lobbying in favor of climate change legislation by around 70 percent when compared with the observed base rate of lobbying. ${ }^{45}$ Although these estimates are purely correlational and should be interpreted with care, they are suggestive of exactly the relationship between firm competition and political behavior described earlier in the formal model. Appendix B1 contains the full results of both models along with additional results confirming the robustness of the findings. ${ }^{46}$

Before moving to the analysis of an open economy setting I briefly note two additional results. Let $F_{i}>2 F_{j}$ so that $\gamma_{i}>0$. One question with implications for the design of climate change regulation is how increasing or decreasing heterogeneity in adjustment costs would affect equilibrium policymaking. As noted earlier

41. Kim 2017.

42. According to the North American Industry Classification System (NAICS). Availability of covariates significantly reduces the number of observations as described in the empirical results.

43. De Figueiredo and Richter 2014; Olson 1971.

44. Garcia-Johnson 2000.

45. In contrast the coefficient estimate corresponding to the emissions intensity of each firm's own zip code is relatively small and does not achieve statistical significance. This surprising result again suggests that it is relative rather than absolute adjustment costs that influence firms' political behavior: the effect of being located in a high-cost area may be mediated by a firm's competitive position on other dimensions such as the age or efficiency of production facilities.

46. Employing the rare events correction described in King and Zeng 2003 or excluding extreme outliersdefined as those with residuals greater than three times the standard deviation-does not change the results. Firms may lobby not only to pass legislation but also to achieve more narrow particularistic benefits relevant to their industry. Taking a variety of these industry-specific provisions into account does not alter the finding nor does controlling for state-level renewable energy standards as a proxy for prior exposure to environmental regulation. See Tables 2-5 in Appendix B1. 
equilibrium regulation depends on both average and relative marginal costs of regulation. These two quantities are closely linked. Suppose that $\gamma_{i}>0$ so that firm $i$ has lower adjustment costs than firm $j$. Increasing $F_{i}$ has the dual effect of decreasing average adjustment costs and increasing firm heterogeneity. Both of these effects tend to increase equilibrium regulation. Thus in this case a decrease in average adjustment costs is associated with a higher level of regulation.
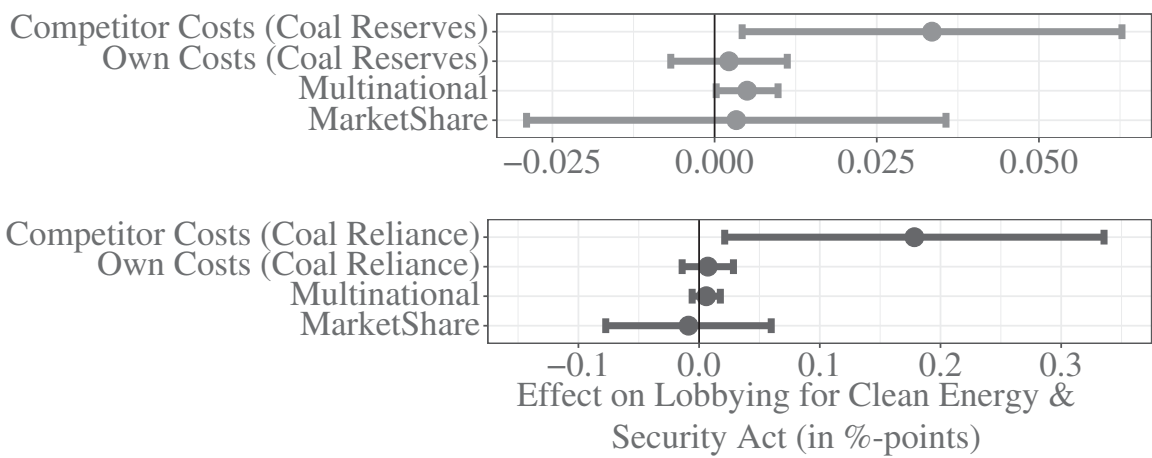

Notes: Marginal (partial) effects for the average firm in the sample, including 95\% confidence intervals. Logistic regression with standard errors clustered by industry. Dependent variable is support for H.R.5424, The American Clean Energy and Security Act of 2009. Competitor Costs (Coal Reliance) is share of competitors located in high-adjustment-cost zip codes as measured by carbon intensity of electricity generation. Competitor Costs (Coal Reserves) is share of competitors in high-adjustment zip code as measured by the presence of coal reserves. Omitted covariates include PRODUCTIVITY, NET PP\&E, MARKET CAP, ENERGY INTENSIVE MANUFACTURING, and ELECTRICITY PROVIDER. Marginal effects calculated using the mfx package in R. Sample size for each analysis consists of 2,722 and 531 observations respectively, reflecting limitations in the availability of zip-code-level measures of carbon usage for electricity generation. See Appendix B1 for additional discussion.

FIGURE 6. Marginal effects of key variables for an average firm

Consider instead a decrease in the adjustment costs for firm $j$. Again this has the effect of lowering average costs of regulation. This should lead to a higher level of equilibrium regulation, all else equal. Yet increasing $F_{j}$ also has implications for firm heterogeneity: by decreasing the distance between firms' adjustment costs, an increase in $F_{j}$ reduces firm $i$ 's incentive to lobby in favor of climate change legislation. This exerts a countervailing effect on equilibrium regulation. The overall effect of increasing $F_{j}$ then depends on the relative strength of these two dynamics. Proposition 3 establishes that in some cases the latter may outweigh the former: increasing $F_{j}$ reduces average adjustment costs, yet leads to strictly lower equilibrium regulation.

Proposition 3. There exists a competitive equilibrium in which regulation is strictly decreasing in the less competitive firm's green capital.

Proposition 3 suggests that the allocation of free permits or other subsidy-like aspects to climate change regulation can have significant implications for the emergence of 
private sector support. These measures are often seen as key to the political success of climate change legislation. The result takes on particular significance in the context of international negotiations in which climate finance has traditionally played a central role. A key achievement of the Paris Agreement is the commitment by developed countries to provide around USD 100 billion annually in funds to assist developing countries in mitigation and adaptation. Figure 7 depicts the distribution of climate finance already disbursed at the time of Paris negotiations. Proposition 3 suggests that the allocation of these funds within developing countries' domestic economies will have significant implications for the balance of support or opposition for climate change commitments in the developing world.

The final result establishes an important connection between policymakers' ideology and firms' propensity to support climate change legislation and adds additional support to the empirical plausibility of the model. Earlier I described several examples of firm lobbying in favor of climate change legislation. Yet as noted the emergence of green lobbying, at least in the United States, represents a relatively new phenomenon. Proposition 4 provides insight into the emergence of this phenomenon, establishing a relationship between the policymaker's own preference and the emergence of green lobbying.

Proposition 4. Consider a sequence of ideal points $\left\{r_{n}^{P M}\right\}_{n \in N}$ converging to 0 . There exists a corresponding sequence of competitive equilibria in which (i) equilibrium regulation converges to 0 , (ii) firm i's equilibrium contribution converges to 0 , and (iii) firm j's equilibrium contribution is bounded strictly away from 0.

Recall that in selecting a level of regulation the policymaker balances his own preferred policy against the preferred policy of the firms providing campaign contributions. In equilibrium the policymaker equates his marginal loss from selecting a policy other than his (ideologically driven) ideal point with the marginal gain in campaign contributions accruing from the two firms. The marginal change in campaign contributions is given by the sum of the marginal changes in firm profitability given contribution schedules that are locally truthful.

Proposition 4 applies when this aggregate change in firms' profitability is strictly negative. ${ }^{47}$ Since regulation increases costs of production and thus prices for consumers, it reduces overall firm profitability. For a positive level of regulation to prevail it must be the case that the policymaker has a positive marginal value for regulation, offsetting these economic losses. The surprising result related to firm lobbying is that even when the policymaker holds no value for regulation, the antiregulation firm must still offer contributions to deter lobbying from green firms that might otherwise-in isolation-induce a

47. Regulation is inefficient provided that firm heterogeneity is not too great. Formally this implies an upper bound on $\gamma_{i}$. 


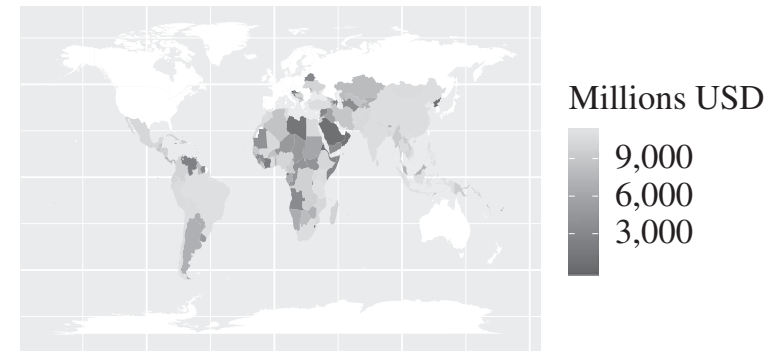

Climate Finance (Principal Objective)

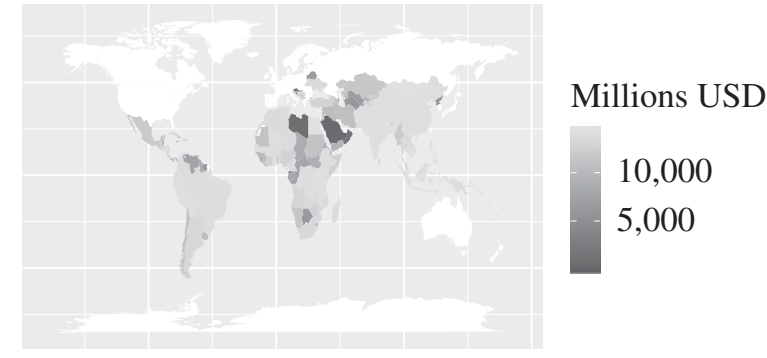

Climate Finance (Significant Objective)

FIGURE 7. OECD climate finance, 2002-2016 (in millions USD) 
skeptical policymaker to depart from his ideal policy of 0 and implement a positive level of regulation. ${ }^{48}$

To illustrate the logic of this result, consider firm lobbying on climate change policy during the Bush administration, the vast majority of which was carried out exclusively by firms opposed to US participation in the Kyoto Protocol. One oil industry group, the Global Climate Coalition (GCC) was particularly instrumental in the administration's decision to withdraw from the treaty. As noted in official documents released under a Freedom of Information Act (FOIA) request, Paula Dobriansky, then US under-secretary of state, is noted as thanking the GCC for its "active involvement" and confirming that "Potus rejected Kyoto in part based on input from you." 49

This was the case despite the administration's own predisposition against climate change regulation. Climate and energy policy fell under the portfolio of then Vice President Dick Cheney, a notorious opponent of climate change policy. ${ }^{50}$ Cheney appointed Jim Connaughton as chairman of the Council on Environmental Quality who made it his mission to obstruct any progress on climate change regulation, even appointing a former employee of the American Petroleum Institute (one of the core founders of the GCC) as his top deputy. While utilities companies and other manufacturers were also outspoken in their opposition to climate change policy there is no evidence of significant counter-vailing pressure from supportive firms, consistent with the predictions of Proposition 4. ${ }^{51}$

\section{Green Lobbying in an Open Economy}

\section{Trade Openness}

Here I consider the implications of green lobbying in an open economy setting. ${ }^{52}$ First I consider the case of import competition. Because foreign firms produce abroad, they are not subject to national regulation. Yet they may sell in the domestic market, potentially undercutting those firms whose costs are affected by regulatory choices. Let there be a set of domestic firms $\mathcal{M}$ where $|\mathcal{M}|=M>1$. Suppose

48. A small modification to the model makes clear that green lobbying may be suppressed entirely for a range of policymaker ideal points. Suppose that firms must each pay a fixed lobbying cost, $\psi>0$, in order to participate in the political process. For any such fixed cost, there exists an interval $\left(0, \bar{r}^{P M}\right)$ with $\bar{r}^{P M}>0$ such that if the policymaker's ideal point falls within this interval, then in the resulting equilibrium, firm $i$ chooses not to lobby while firm $j$ continues to do so.

49. John Vidal, "Revealed: How Oil Giant Influenced Bush,” The Guardian, 8 June 2005.

50. Coll 2013.

51. Tim Dickinson, "Six Years of Deceit: Inside the Bush Administration's Secret Campaign to Deny Global Warming and Let Polluters Shape America's Climate Policy," Rolling Stone, 28 June 2007.

52. Throughout I maintain the assumption that the value of the relevant market is bounded below, $\alpha>\bar{\alpha}$ as in the closed economy setting. This assumption ensures that all firms produce positive output in equilibrium and eliminates the possibility of endogenous monopoly under which no possibility of green lobbying exists. 
there are a total of $N$ firms competing in the market, implying that $N-M$ of these are foreign competitors. Domestic firms have marginal cost of production as above with green capital $F_{i}$ for each $i \in \mathcal{M}$. Production costs of importers are unaffected by the level of regulation in the economy, but they face a symmetric per-unit transportation cost, $\tau>0 .{ }^{53}$ Each active firm announces contribution schedule $s_{i}: \mathbb{R}^{+} \rightarrow \mathbb{R}^{+}$and selects a level of output $q_{i}$. Again, I assume that $\alpha$ is sufficiently large that all incumbent firms choose to continue production even under the most stringent possible regulatory outcome. ${ }^{54}$ All other aspects of the game remain as before.

By increasing marginal production costs for domestic firms only, climate change regulation clearly worsens these firms' competitive position relative to foreign competitors. Nonetheless, as the next result establishes, domestic firms may continue to support higher levels of climate change regulation. Denote by $F_{-i}^{M}$ the harmonic mean of green capital among firm $i$ 's domestic competitors, $j \in \mathcal{M} \backslash i{ }^{55}$

Proposition 5. Domestic firm i lobbies in favor of climate change regulation if and only if $F_{i} \geq \frac{N}{M-1} F_{-i}^{M}$.

Proposition 5 establishes the robustness of green lobbying to the presence of import competition. Moreover it highlights the relative importance of domestic versus foreign competitors in shaping firm preferences. The right-hand side of Proposition 5 consists of two components. The first corresponds to the (inverse) proportion of firm $i$ 's competitors subject to domestic regulation. The second term describes the distribution of green capital among these domestic competitors. Firm $i$ 's support for climate change regulation depends not only on the relative market share of foreign firms but also its competitiveness with respect to the domestic firms.

The case of export competition differs from that of import competition in that exporting firms now compete with their domestic competitors both at home and in some cases abroad in the foreign market. Again, foreign firms themselves will be unaffected by domestic climate change regulation. Yet climate change regulation will shift the market share of domestic firms both at home and abroad. Again denote the set of domestic firms $\mathcal{M}$ with $|\mathcal{M}|=M$. An exogenously given subset of these firms, $\mathcal{K}$, also engages in export to a single foreign market, where $|\mathcal{K}|=K>1$. Let the set of foreign incumbent firms in that market be $\mathcal{J}$ with $|\mathcal{J}|=J$. Inverse demand in the foreign market is given by $p(\boldsymbol{q})=\alpha^{*}-\sum_{j \in \mathcal{J}} q_{j}-\sum_{k \in \mathcal{K}} q_{k} .{ }^{56}$ The

53. I normalize all other marginal production costs of foreign firms to 0 for simplicity. Alternatively let $\tau=\tau^{*}+c\left(q_{j}\right)$ denote the total (constant) marginal cost for foreign firm $j$. Note that I adopt a partial equilibrium approach consistent with Helpman and Krugman 1985 for simplicity.

54. This requires $\alpha>R\left(\frac{N}{F_{j}}-\sum_{\mathcal{M} \backslash j} \frac{1}{F_{m}}\right)$ where $j$ is assumed to have the lowest level of green capital among all domestic firms.

55. That is $\frac{1}{\frac{1}{M-1} \sum_{j \in \mathcal{M} \backslash i^{\frac{1}{F}}}}$.

56. I again require $\alpha^{*}>\tau R\left(\frac{K}{F_{j}}-\sum_{\mathcal{K} \backslash j} \frac{1}{F_{k}}\right)$ to ensure that even the worst-off firm (denoted as usual by $j$ ) continues to engage in export under the most stringent possible regulatory regime. 
marginal production cost of foreign firms is constant and given by $\phi>0$. Thus foreign production costs are independent of the level of domestic regulation and symmetric across firms.

Exporting firms incur higher variable costs in serving the foreign market relative to the domestic market. This additional cost may stem from transportation goods, trade policy in the destination country, or increased frictions of operating in a foreign market. The cost to domestic firms of exporting $q_{j}$ units is $\frac{r \tau}{F_{i}} \cdot q_{j}$ where $\tau>1$. Production costs and competition in the domestic market-as well as all other features of the game-remain the same. Domestic firm profits are now given by the sum of profits in the domestic market, $\pi_{i}^{d}$, and in the export market, $\pi_{i}^{e}$.

Note that higher levels of climate change regulation will necessarily decrease the collective market share of exporting firms in the foreign market given their now higher marginal costs across the board. Nonetheless the next result establishes that individual exporters may still benefit from higher levels of regulation. Even where this does not occur, gains in the domestic market may continue to compensate exporting firms for competitive losses in the export market. Let $F_{-i}^{K}$ denote the harmonic mean of green capital among firm $i$ 's export competitors and assume that $F_{-i}^{K}>F_{-i}^{M} .{ }^{3}$

\section{Proposition 6. For any $i \in \mathcal{K}$}

\section{Export profits are increasing in $r$ if and only if $F_{i} \geq \frac{J+K}{K-1} F_{-i}^{K}$.}

2. Firm $i$ lobbies in favor of climate change regulation if and only if $F_{i} \geq F_{i}^{*}$ for some $F_{i}^{*} \in\left(F_{-i}^{M}, F_{-i}^{K}\right)$.

The first part of Proposition 6 establishes that increases in climate change regulation may increase not only domestic profits but also export profits for firms with high levels of green capital relative to other exporters. Similar to the case of import penetration, if these shifts in market share are sufficiently large they may compensate exporting firms for losses relative to foreign competitors. The second part of Proposition 6 establishes that exporting firms may support climate change regulation, even where the first condition does not hold. If firm $i$ 's advantage in terms of green capital is sufficiently large relative to its domestic competitors, then gains in the domestic market can offset overall losses in the export market. In this case, exporting firms' incentives to support climate change regulation reflect both the market share of domestic firms abroad as well as the distribution of green capital with respect to exporting firms, $\mathcal{K}$, and the full population of domestic firms, $\mathcal{M}$.

Figure 8 explores the interaction of competitor costs and trade exposure empirically by adding an interaction term to the model, the results of which are depicted

57. This is equivalent to assuming that only the most productive domestic firms engage in export, consistent with the findings of Melitz 2003. 


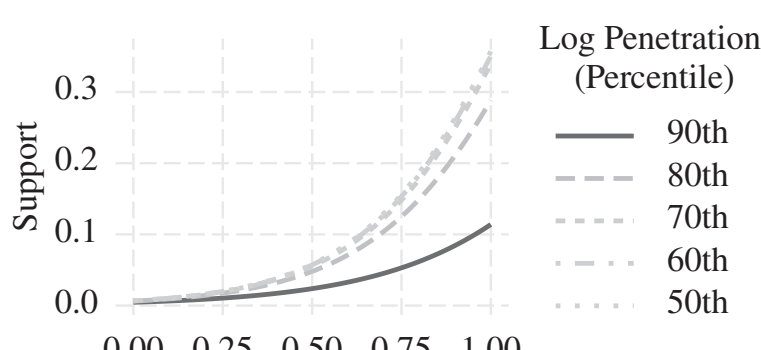

$\begin{array}{lllll}0.00 & 0.25 & 0.50 & 0.75 & 1.00\end{array}$

Competitor Costs (Coal Reserves)

(a)

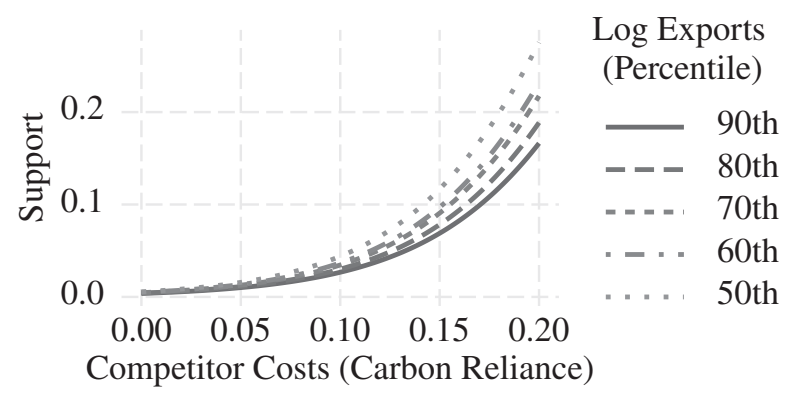

(c)

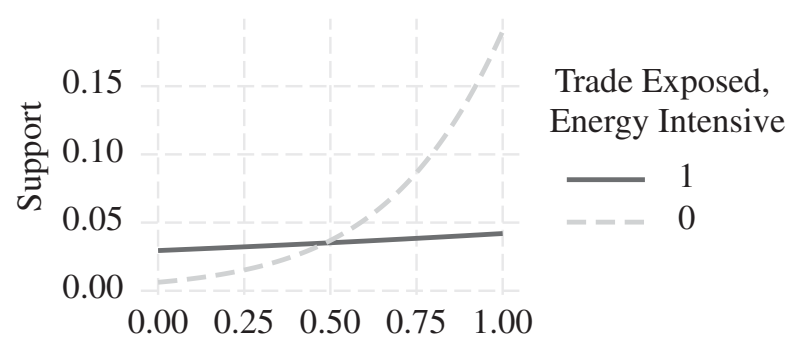

Competitor Costs (Coal Reserves)

(b)

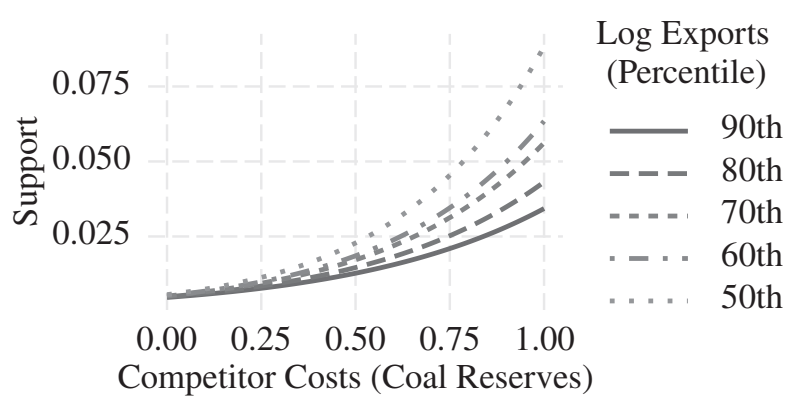

(d)

Notes: Estimated effect of competitor costs, conditional on levels of import penetration with all other variables mean centered. Panel (b) depicts the same for industries that are both trade exposed and energy intensive versus those not. Panels (c) and (d) again model conditional effect of competitor costs, fixing (logged) exports and employing carbon intensity and coal reserves respectively as the measure of competitor costs. All coefficients estimated employing a similar regression to that in Figure 6 but interacting Competitor Costs with the respective import and export variables. All other variables are held at their mean.

Trade data obtained from UN COMTRADE. Plots generated using the jtools package in R. Sample size for panels (a), (b), and (d) consists of 2,722 observations. Sample size for panel (c) consists of only 531 observations. Full results of each specification are included in Table 6 of Appendix B1.

FIGURE 8. The moderating effects of foreign competition 
in Figure 6. Panel (a) depicts the estimated effect of competitor costs conditional on import penetration. The association between competitor costs and the probability of supporting climate change legislation remains relatively stable up through the eightieth percentile by (logged) import penetration. Following this the correlation is significantly attenuated. Panel (b) depicts the same, but including separate estimates for firms that are both trade exposed and energy intensive. For these firms, there is little association between competitor concerns and supportive lobbying, perhaps reflecting these firms' overall propensity to lobby in favor, given the special provisions for them included in the final legislation.

Panels (c) and (d) again depict the estimated effect of competitor costs, conditional on (logged) exports. I employ carbon intensity and coal reserves respectively as alternative measures of competitor costs. In these cases while higher levels of (logged) exports similarly lead to attenuation, the effect is smoother and less dramatic than in the case of imports. While the statistical tests are inconclusive-the moderating effects depicted in either case are not statistically significant-descriptively the patterns revealed in the data are consistent with the idea that supportive lobbying depends on both the relative share of foreign versus domestic competitors and each firm's competitive position relative to the domestic industry. ${ }^{58}$

\section{Vertical Integration and Outsourcing}

Next I develop a model of green lobbying in the presence of global value chains. ${ }^{59}$ Let firms $i \in\{1,2\}$ produce good $q_{i}$ using an intermediate input $m_{i}$ and headquarter services $h_{i}$. I assume that firm 1 purchases the intermediate good abroad either via outsourcing $(\mathrm{O})$ or vertical integration $(\mathrm{V})$. Firm 2 purchases the intermediate good domestically, again either via outsourcing or vertical integration. Denote each firm's organizational structure by $k_{i} \in\{V, O\}$. The marginal cost of the intermediate good differs according to its production location. If the intermediate good is produced at home its marginal cost is $r \phi$ for some $\phi>0$ whether production takes place internally $\left(k_{2}=V\right)$ or externally $\left(k_{2}=O\right)$. If the intermediate good is produced abroad its marginal cost is $\phi^{*}$ again regardless of organizational structure. ${ }^{60}$ In either case a firm purchasing the intermediate good abroad also pays per unit transportation cost $\tau>0$. Let $\theta>0$ be the (symmetric) cost of headquarter services.

58. In both specifications the coefficient estimate for COMPETITOR COSTS maintains its statistical significance. All model results are reported in Table 6 of Appendix B1.

59. I build directly on the global sourcing model of Antràs and Helpman, 2004. That paper endogenizes firm sourcing decisions while I take these as exogenous, analyzing instead implications of organizational structure for firm policy preferences.

60. I take the organizational structure of firms to be exogenous though, consistent with Antràs and Helpman 2004, the choice to vertically integrate implicitly reflects frictions in the contracting environment rather than returns to scale which would imply asymmetric marginal costs across organizational structures. In contrast to Antràs and Helpman I assume that intermediate good producers and headquarters choose output levels cooperatively. 
Production is Cobb-Douglas and given by

$$
q_{i}\left(h_{i}, m_{i}\right)=A_{i}\left(\frac{h_{i}}{\eta}\right)^{\eta}\left(\frac{m_{i}}{1-\eta}\right)^{1-\eta}
$$

where $A_{i}>0$ is each firm's overall productivity and $\eta>0$ is the output elasticity of headquarter services. To emphasize the role of organizational structure and sourcing decisions as opposed to innate differences in productivity I normalize $A_{1}=A_{2}=1$. Each firm simultaneously chooses how much of the intermediate good $m_{i}$ to purchase (or produce in the case of vertical integration) and final output levels $q_{i} \cdot{ }^{61}$

Neither firm can write enforceable ex ante contracts with independent intermediate goods producers but instead bargain over ex post profits. In the case of vertical integration profits are determined again by ex post bargaining between headquarters and its subsidiary. As a result of bargaining firm $i$ retains share, $S_{k}$, of total profits for $k \in\{V, O\} .^{62}$ Vertical integration implies greater bargaining power on the part of headquarters via a residual claim on the subsidiary's production of the intermediate good. ${ }^{63}$ Thus I assume $S_{V}>S_{O}$. Proposition 7 establishes the core result in the model with differential sourcing.

Proposition 7. Firm 1 lobbies in favor of climate change regulation regardless of its organizational structure while firm 2 lobbies against. Both firms lobby more intensively under vertical integration than under outsourcing.

As in the case of import competition, firm 1's production is unaffected by the domestic level of regulation while firm 2 is adversely affected. Firm 1 enjoys gains in market share from increases in regulation without incurring any additional costs providing clear incentive to support climate change regulation for competitive reasons. Firm 2 by contrast loses out both from direct increases in its operating costs and erosion of its competitive position relative to firm 1. Moreover, as vertically integrated firms enjoy a greater share of operating profits they exhibit greater preference intensity than their counterparts who source externally.

This last result suggests an alternative explanation for the observed activism of multinational corporations (by nature vertically integrated) on climate change policy. While there is already a broad consensus in the literature that multinational corporations are more likely to support climate change legislation, the mechanism advanced here is very different than the conventional wisdom. ${ }^{64}$ Vertically integrated firms may gain from regulatory divergence if regulation increases the costs of their competitors' intermediate goods.

61. As in the cases before I ensure that both firms choose to produce in equilibrium by assuming $\alpha>\theta^{\eta}\left[(R \phi)^{(1-\eta)}-\left(\tau \phi^{*}\right)^{(1-\eta)}\right]$ and $\tau$ sufficiently small.

62. Allowing these shares to vary according to production location does not alter the results.

63. Grossman and Hart 1986.

64. Garcia-Johnson 2000. 


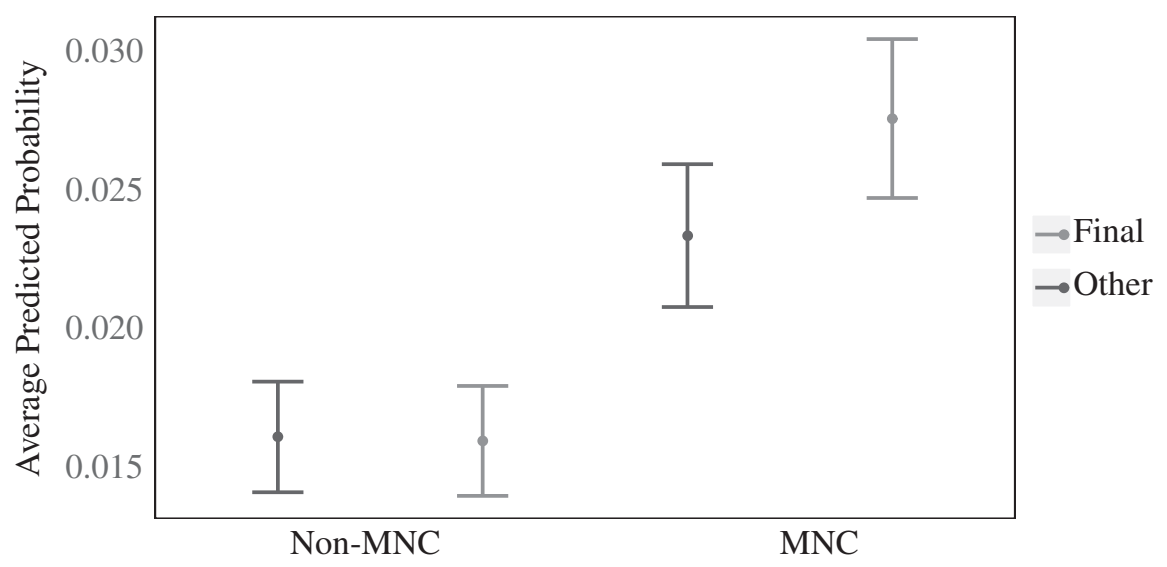

Notes: Mean predicted probability of lobbying for nonmultinationals versus multinationals as moderated by production stage. The difference in means between multinationals engaged in final goods production and those engaged in other stages of production is statistically significant at the 0.01 level. Note that base rate of lobbying is 0.008 accounting for the relatively small scale of the estimates. Estimates based on the same sample and variables employed in the analysis depicted in Figure 6 with the addition of an interaction between MNC and an indicator for final goods producers, where the latter is defined according to UN Broad Economic Categories (BEC). Estimation via biased reduced logistic regression (Firth 1993) employing the brglm package in $\mathrm{R}$.

\section{FIGURE 9. Moderating effects of production stage}

Evidence for this particular mechanism can be found by comparing the lobbying of multinational corporations engaged in final goods production with those engaged in other stages of production. Proposition 7 suggests that multinationals should exhibit greater preference intensity for climate change regulation in markets where they engage in final goods production. While some domestic firms engaged in outsourcing may also prefer higher levels of climate change regulation, the intensity of these preferences will be lower and, furthermore, diluted in the data by domestic firms engaged in final goods production but reliant on domestic and therefore higher expected intermediate goods prices.

Again building on my analysis, I provide statistical evidence consistent with this prediction in Figure 9. The figure depicts the predicted probability of lobbying by both multinational and domestic firms by production stage. I obtained these estimates by interacting MNC status with an indicator for final goods production employing the same lobbying data and covariates described in Figure 6. The measure of final goods production is based on industry and defined according to the UN Broad Economic Categories (BEC). ${ }^{65}$ The mean predicted probability of lobbying by multinationals 
is higher for those engaged in final goods production, and the difference in the two means is statistically significant at the 0.01 level. This suggests that the widespread finding that MNC's are more likely to lobby in favor of climate change may in part be driven by firms engaged in final goods production and thus unlikely to be subject to regulations affecting earlier, more energy-intensive production stages. ${ }^{66}$

\section{Conclusion}

Why do some firms support national climate change regulation despite its economic costs? Firms' embrace of environmental regulation is all the more puzzling in a globalized economy where national regulation may undermine domestic firms' competitiveness relative to foreign competitors and where differences in cross-national regulatory regimes increase transaction costs for multinational corporations operating across state lines. I argue that firms support climate change legislation to gain advantage over domestic market competitors and that these gains may even offset competitive losses relative to foreign firms. In a closed economy model of policymaking and market competition I show that firms holding an advantage in adjustment costs may see increased profits following the introduction of carbon regulation and thus find it optimal to invest resources in lobbying in support of the new regime. This conclusion is supported by statistical analysis of firms' lobbying in favor of US climate change legislation.

These same intuitions carry over to an open economy setting where firms facing import penetration - or engaged in export competition-may find it optimal to support climate change regulation despite competitive losses relative to foreign firms. Willingness to do so in either case depends on the relative market share (at home or abroad) of domestic competitors as well as the distribution of green capital among those competitors. Contrary to existing literature, the analysis demonstrates that the impact of foreign competition on firm preferences for climate change policy depends on competitive dynamics in the domestic market. Finally in the context of global value chains I show that multinational corporations are more likely to support efforts to mitigate global climate change if those efforts raise the costs of domestically produced intermediate goods, providing an alternative to the conventional wisdom that MNCs support climate change regulation in order to bring about harmonization of national policies. Statistical analysis of multinational lobbying behavior provides support for this prediction.

The arguments and empirical evidence I've presented have implications for the domestic political economy of climate change, the environmental effects of open

described in Firth 1993 and implemented via the brglm package in R. The advantage of the bias-reduction method is that it produces finite confidence intervals even in the presence of separation.

66. The difference in means between multinationals and domestic firms engaged in either final goods production or other stages is likewise statistically significant at the 0.01 level. 
borders, and the study of firms in international cooperation. Existing accounts of firm support for climate change regulation rely on idiosyncratic features of regulatory design or the sequencing of regulation across countries. The benchmark results provide a more general explanation for the emergence of support for climate change legislation. Competition between domestic firms is a sufficient condition for supportive lobbying in nearly any regulatory context. Given the obstructionist policies of the United States, the substantive implications of this argument suggest that pressure for climate change regulation need not rely on leadership by the world's remaining super power, but can arise endogenously as a result of competitive dynamics between firms.

Turning to the perennial question of how globalization affects environmental welfare, my arguments suggest that the overall effect is more complex than has been appreciated thus far. Open borders do not necessarily dampen support for climate change policy and in some cases may provide special impetus for firms to come out in favor of national regulations. The equilibrium effect of open borders on climate change policy depends heavily on the location of various stages of production around the world and the design of global value chains. US domestic regulation may be undermined by carbon leakage, yet carbon leakage may also increase the likelihood of passing climate change legislation in one of the world's largest emitters of carbon dioxide.

Finally, the current work builds on existing models of open economy politics by incorporating insights from the growing literature on intra-industry heterogeneity. In spite of recent advances in the field in firm-level analysis of policy preferences, existing work in this area has yet to appreciate the importance of intra-industry variation with respect to domestic competitors. ${ }^{67}$ The arguments here show that firm preferences for international cooperation will be shaped by their competitive position with respect to both domestic and foreign competitors. Analyses that ignore these considerations may systematically misclassify the winners and losers from cooperation. Future work could explore the implications of these arguments for other policy areas with implications for competition across borders.

\section{Data Availability Statement}

Replication files for this article may be found at <https://doi.org/10.7910/DVN/ 26HDEO>.

\section{Supplementary Material}

Supplementary material for this article is available at <https://doi.org/10.1017/ S0020818320000107>. 


\section{References}

Aklin, Michael. 2016. Re-exploring the Trade and Environment Nexus Through the Diffusion of Pollution. Environmental and Resource Economics 64 (4):663-82.

Alcoa Corporation. 2017. Form 10-K. United States Securities and Exchange Commission.

Aluminum Association. 2009. Aluminum Statistical Review for 2008.

Ameren Corporation. 2011. Form 10-K. United States Securities and Exchange Commission.

Antràs, Pol, and Elhanan Helpman. 2004. Global Sourcing. Journal of Political Economy 112 (3):552-80.

Bechtel, Michael M., Federica Genovese, and Kenneth Scheve. 2019. Interests, Norms, and Mass Support for Global Climate Cooperation. British Journal of Political Science 49 (4):1333-55.

Bernheim, B. Douglas, and Michael D. Whinston. 1986. Menu Auctions, Resource Allocation, and Economic Influence. The Quarterly Journal of Economics 101 (1):1-32.

Bonica, Adam. 2017. Replication Data for Avenues of Influence: On the Political Expenditures of Corporations and Their Directors and Executives. Available at <https://doi.org/10.7910/DVN/ 6R1HAS>.

Chaney, Thomas. 2008. Distorted Gravity: The Intensive and Extensive Margins of International Trade. American Economic Review 98 (4):1707-21.

Coll, Steve. 2013. Private Empire: ExxonMobil and American Power. Penguin Books.

De Figueiredo, John M., and Brian Kelleher Richter. 2014. Advancing the Empirical Research on Lobbying. Annual Review of Political Science 17:163-85.

Entergy Corporation. 2009. Entergy Chairman and CEO Announces Support for Climate Change Bill. PR Newswire.

Eurometaux. 2015. COP 21: Why It's Time for a Level Playing Field. Available at $<$ https://eurometaux.eu/ blog/cop-21-why-its-time-for-a-level-playing-field/>.

Firth, David. 1993. Bias Reduction of Maximum Likelihood Estimates. Biometrika 80 (1):27-38.

Garcia-Johnson, Ronie. 2000. Exporting Environmentalism: US Multinational Chemical Corporations in Brazil and Mexico. MIT Press.

Genovese, Federica. 2018. Market Responses to Global Governance: International Climate Agreements and Europe's Carbon Trading. Working Paper.

Genovese, Federica. 2019. Sectors, Pollution, and Trade: How Industrial Interests Shape Domestic Positions on Global Climate Agreements. International Studies Quarterly 63 (4):819-36.

Genovese, Federica, and Endre Tvinnereim. 2018. Who Opposes Climate Regulation? Business Preferences for the European Emission Trading Scheme. Review of International Organization 14 (3):511-42.

Green, Jessica F. 2013. Rethinking Private Authority: Agents and Entrepreneurs in Global Environmental Governance. Princeton University Press.

Grossman, Gene, and Elhanan Helpman. 1992. Protection For Sale. American Economic Review 84 (4): 833-50.

Grossman, Gene M., and Elhanan Helpman. 2001. Special Interest Politics. MIT Press.

Grossman, Sanford J., and Oliver D. Hart. 1986. The Costs and Benefits of Ownership: A Theory of Vertical and Lateral Integration. Journal of Political Economy 94 (4):691-719.

Hadden, Jennifer. 2015. Networks in Contention. Cambridge University Press.

Hadden, Jennifer, and Lorien Jasny. 2019. The Power of Peers: How Transnational Advocacy Networks Shape NGO Strategies on Climate Change. British Journal of Political Science 49 (2):637-59.

Helpman, Elhanan, and Paul Krugman. 1985. Market Structure and Foreign Trade: Increasing Returns, Imperfect Competition, and the International Economy. MIT Press.

Kang, Karam. 2015. Policy Influence and Private Returns from Lobbying in the Energy Sector. The Review of Economic Studies 83 (1):269-305.

Kenworthy, Tom. 2009. A Renewable Energy Standard: The Proof Is in the States. Center for American Progress, 19 May. Available at <https:/www.americanprogress.org/issues/green/news/2009/05/19/ 6027/a-renewable-energy-standard-the-proof-is-in-the-states/>. 
Kim, In Song. 2017. Political Cleavages Within Industry: Firm-level Lobbying for Trade Liberalization. American Political Science Review 111 (1):1-20.

King, Gary, and Langche Zeng. 2003. Logistic Regression in Rare Events Data. Journal of Statistical Software 8 (2):137-63.

Kleemann, Linda, and Awudu Abdulai. 2011. The Impact of Trade and Economic Growth on the Environment: Revisiting the Cross-Country Evidence. Journal of International Development 25 (2):180-205.

Kothari, S.P., and Jerold B. Warner. 2007. Econometrics of Event Studies. In Handbook of Corporate Finance, Volume 1, edited by B. Espen Eckbo, 3-36. Elsevier B.V.

Lake, David A. 2009. Open Economy Politics: A Critical Review. The Review of International Organizations 4 (3):219-44.

Laws, Forrest. 2009. Climate Change Bill Dividing Farm Groups? Southwest Farm Press.

Liston-Heyes, Catherine, and Anthony G. Heyes. 1999. Corporate Lobbying, Regulatory Conduct and the Porter Hypothesis. Environmental and Resource Economics 13 (2):209-18.

Lizza, Ryan. 2010. As the World Burns: How the Senate and the White House Missed Their Best Chance to Deal with Climate Change. The New Yorker, 3 October. Available at $<$ https://www.newyorker.com/ magazine/2010/10/11/as-the-world-burns>.

Melitz, Marc J. 2003. The Impact of Trade on Intra-Industry Reallocations and Aggregate Industry Productivity. Econometrica 71 (6):1695-725.

Michaelis, Peter. 1994. Regulate Us, Please! On Strategic Lobbying in Cournot-Nash Oligopoly. Journal of Institutional and Theoretical Economics 150 (4):693-709.

Nehrt, Chad. 1998. Maintainability of First Mover Advantages When Environmental Regulations Differ Between Countries. The Academy of Management Review 23 (1):77-97.

Noranda Aluminum Holding Corporation. 2009. Form 10-K. United States Securities and Exchange Commission.

Olson, Mancur. 1971. The Logic of Collective Action. Harvard University Press.

Osgood, Iain, Dustin Tingley, Thomas Bernauer, In Song Kim, Helen V. Milner, and Gabriele Spilker. 2017. The Charmed Life of Superstar Exporters: Survey Evidence on Firms and Trade Policy. The Journal of Politics 79 (1):133-52.

Oster, Sharon. 1982. The Strategic Use of Regulatory Investment by Industry Sub-groups. Economic Inquiry 20 (4):604-18.

Peters, Glen P., Jan C. Minx, Christopher L. Weber, and Ottmar Edenhofer. 2011. Growth in Emission Transfers Via International Trade From 1990 to 2008. Proceedings of the National Academy of Sciences 108 (21):8903-908.

Porter, Michael, and Claas van der Linde. 1995a. Toward a New Conception of the EnvironmentCompetitiveness Relationship. Journal of Economic Perspectives 9 (4):97-118.

Porter, Michael E., and Claas van der Linde. 1995b. Green and Competitive: Ending the Stalemate. Harvard Business Review 73:120-34.

Rogerson, William P. 1984. A Note on the Incentive for a Monopolist to Increase Fixed Costs as a Barrier to Entry. The Quarterly Journal of Economics 99 (2):399-402.

Salop, Steven C., and David T. Scheffman. 1983. Raising Rivals' Costs: Recent Advances in the Theory of Industrial Structure. American Economic Review 73 (2):267-71.

Salop, Steven C., and David T. Scheffman. 1987. Cost-Raising Strategies. The Journal of Industrial Economics 36 (1):19-34.

Silgan Holdings Inc. 2017. Form 10-K. United States Securities and Exchange Commission.

Skocpol, Theda. 2013. Naming the Problem: What It Will Take to Counter Extremism and Engage Americans in the Fight Against Global Warming? Manuscript Prepared for the Symposium on the Politics of America's Fight Against Global Warming.

Stigler, George J. 1971. The Theory of Economic Regulation. The Bell Journal of Economics and Management Science 2 (1):3-21.

US CAP. 2009. A Blueprint for Legislative Action: Consensus Recommendations for US Climate Protection Legislation. US Climate Action Partnership. 
Vogel, David. 1997. Trading Up: Consumer and Environmental Regulation in a Global Economy. Harvard University Press.

Yeatman, William. 2011. The Progressive Case for HB 1240. Energy Policy Center.

\section{Author}

Amanda Kennard is Assistant Professor in the Wilf Family Department of Politics at New York University. She can be reached at kennard@nyu.edu.

\section{Acknowledgments}

For helpful comments and suggestions I thank Helen Milner, Matias Iaryczower, Kris Ramsay, Eric Arias, Felipe Balcazar, Lawrence Broz, Ryan Brutger, Ted Enamorado, Germán Gieczewski, Bob Keohane, James Lee, Melissa Lee, John Londregan, Julia Morse, David Stasavage, Saurabh Pant, Tyler Pratt, Yuki Shiraito, Sondre Solstad, and B. Peter Rosendorff.

\section{Key Words}

Climate change; firms; open economy politics; lobbying

Date received: September 16, 2017; Date accepted: June 1, 2019 